\title{
A Dutch to SQL database interface using Generalized Quantifier Theory
}

\author{
Dirk Speelman ${ }^{[1]} \quad$ Geort $\Lambda$ driaens $^{[1,2]}$ \\ [1] University of Leuven Center for Computational Linguistics, \\ Blijde-Inkomststraat 21, 3000 Leuven, Belgium \\ [2] Siemens-Nixdor[ Software Centre Ijiege, \\ Rue des l'orics 2, 4020 Liège, Belgium
}

\begin{abstract}
This paper presents the treatment of quantification as it was implemented in a prototype of a natural language relational database interface for Dutch ${ }^{1}$. It is shown how the theoretical 'generalized quartifier' apparatus introduced in formal semantics by Barwise and Cooper can be luned to implementational feasibility. Compared to the traditional treatment of quantification, the alternative presented here offers greater expressive power, greater similarity to natural language and, as a consequence, the possibility of a more straightforward transiation from natural language to formal representation.
\end{abstract}

\section{INTRODUCTION}

In the prototype at hand, as in many database interfaces, the natural language input is translated to a conventional formal query language, viz. SQL, the most widely used and supported of these languages. The resulting SQL queries can then be passed to an already existing SQI interpreter.

The translation procedure from 1)utch to SQI, is split up in two consecutive major steps, using a logic-based intermediate somantic representation called General Serrantic Representation (GSR) ${ }^{2}$. The functionality of the whole database interface, including the SQI, interpreter, was seen as a straightforward implementation of the formal semantic Montague-stylo (Montague, 1973) mechanism of indirect interpretation of natural language (see tig. 1).

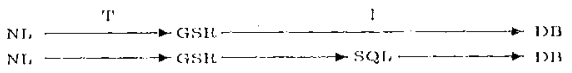

l'igure 1: Major processing steps in the DB interface.

'Grafting' formal semantic processing steps upon an NI, database interface architecture has been propa-

\footnotetext{
${ }^{1}$ Iu this paper the actual implementation is not in focus (seo speelman, 1992)

${ }^{2}$ Within a framework of nachine translation, we can say that GSR is a kind of logic-based interlingua.
}

gated and (succesfully) worked out before in a somewhat comparable project carried out at the university of lissex (sec 1)e Roeck, fox, Lowden, Turner \& Walls, 1991). The main concern in that project was to clearly separate domain (= databasc) dependent semantic information from domain independent semantic information. In the project presented here a similar but more general objective was to maximize the separation of the NLI' data and functionality of the system from its purely database oriented data and functionality, XSR being the interface structure.



Figure 2: General architecture of the program

'The main topic of this paper, treated in section 3, is the application of 'generalized quantifier theory' in GSR. llaving become classical in mathematical and some theoretical linguistic studies on quantification (sec resp. Mostowski, 1957 and Barwise \& Cooper, 1981), the theory is now beginuing to be appreciated in $\Lambda I$ (and NLP) for its riclıness and Rexibility. Probably the best illustration of this upcoming interest is the incorporation of 'generalized quantifiers' in the popular Conceptual Graph knowledge representation formalism (see e.g. Sowa, 1991). A somewhat differently 
oriented $\Lambda$ I-application also using 'generalized quantifiers' can be found in (Kaan, Kas \& Puhland, 1990). These applications concentrate on the expressive and inferential power of 'gencralized quantifier theory' respectively. The program presented here additionally illustrates how the use of (a variant of) the theory reduces the complexity of implementing the translation from natural to formal and artificial language.

\section{GSR: GENERAL OUTLINE}

The question what GSR should look like was to a large extent tackled in a very pragmatical way. As far as the linguistic module of the program is concerned, the following criteria were formulated. GSR had to be a formal representation

(i) with sufficient expressive powcr so that every possibly uscful query can be formulated in it in a not too complex fashion,

(ii) that is relatively easy to reach computationally, starting off from natural language.

A gencral observation is that, considering the kind of NI, sentences one can expect as input to the system, GSR incvitably had to differ from logical formalisms such as the ones used in formal semantics (focussing on propositions). In vicw of the general decision to work with intermediatie semantic expressions the denotation of which is the answer to the NL questions, the basic types of complctc expressions listed in Fig. 3 were found useful. In this figure $\varphi$ stands for an arbitrary proposition in some logical language $L$. The extension of $L$ created by introducing these new types will be called $l$ '.

(i) propositions (format: $\varphi$ ), to be used when people nsk yes-or-no questions

(ii) set expressions (format: $\{x \mid \varphi\}$ ), to be used when people ask non-numerical identity questions

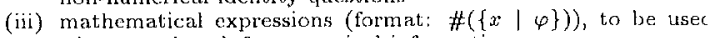
when people ask for numerical information

Figure 3: GSR: types of expressions

\section{FROM DUTCH TO GSR}

\section{1 $\exists$ and $\forall$ : problems}

The traditional. way of coping with quantification in NI, database interfaces is by using $\exists$ and $\forall$, the classical first order predicate logic (PL) instruments (sec e.g. Warren \& Pereira, 1982). This approach, however, does not meet the criteria set out above. 'Io illustrate this, we basically rely on two observations Barwise \& Cooper (1981) made to show a fundamental difference in the natures of NI, and PL. Their observations will be 'transposed' to the computational application at hand.

The first observation is illustrated in figure 4, which contains some Dutch questions and their most natural PL' counterparts. Whereas the Dutch sentences have the same syntactic structure, their PL' counterparts have different formats. These and many other cxamples suggests that there is no trivially compositional way of translating NL expressions to their nearest PL' equivalents. The problem is that the quantificational information, which in NL has a fixed location, is spread over the PL' expression in a secrningly arbitrary way. It may be concluded that criterium (ii) for a good GSR is violated.

\begin{tabular}{|c|c|}
\hline$a+$ & $\begin{array}{l}\text { Zijn alle werknemers gehuwd ? } \\
\text { 'Are all employees married?' } \\
\forall x(\text { employe }(x) \rightarrow \operatorname{married}(x))\end{array}$ \\
\hline$\leadsto$ & $\begin{array}{l}\text { Zijn beide werknemers gehuwd? } \\
\text { 'Are both employees married?' } \\
\exists x_{1}\left(\exists x_{2}\left(\left(x_{1} \neq x_{2}\right) \wedge\right.\right. \\
\text { employec }\left(x_{1}\right) \wedge \text { employec }\left(x_{2}\right) \wedge \\
\forall y\left(\operatorname{cmployec}(y) \rightarrow\left(\left(y=x_{1}\right) \vee\left(y=x_{2}\right)\right)\right) \wedge \\
\left.\left.\text { married }\left(x_{1}\right) \wedge \operatorname{marricd}\left(x_{2}\right)\right)\right)\end{array}$ \\
\hline$\approx+$ & $\begin{array}{l}\text { Zijn prenies drie werknemers Behuwd? } \\
\text { 'Are exactiy three employees married?' } \\
\exists x_{1}\left(\exists x_{2}\left(\exists x_{3}(\right.\right. \\
\left(x_{1} \neq x_{2}\right) \wedge\left(x_{1} \neq x_{3}\right) \wedge\left(x_{2} \neq x_{3}\right) \wedge \\
\text { employee }\left(x_{1}\right) \wedge \text { cmployee }\left(x_{2}\right) \wedge \text { employeo }\left(x_{3}\right) \\
\wedge \forall y((\operatorname{married}(y) \wedge \text { employee }(y)) \rightarrow \\
\left(\left(y=x_{1}\right) \vee\left(y=x_{2}\right) \vee\left(y=x_{3}\right)\right) \wedge \\
\left.\left.\left.\text { marricd }\left(x_{1}\right) \wedge \operatorname{marricd}\left(x_{2}\right) \wedge \operatorname{marricd}\left(x_{3}\right)\right)\right)\right)\end{array}$ \\
\hline 4 & $\begin{array}{l}\text { Tijn meer dan de helft van de } \\
\text { werknemers gehuwd? } \\
\text { 'Are more than half of the employees married?' }\end{array}$ \\
\hline
\end{tabular}

Figure 4: 'Iranslation of quantification from Dutch to PL'

$A$ second, more serious reason for the inadequacy of $\exists$ and $\forall$ is that some forms of NI quantification can only be expressed in a very complex way (e.g. Fig. 4, examples 2 and 3 ) or simply cannot be expressed at all (e.g. lig. 4, example 4). Here criterium (i) is not satisfied

A third problem, mentioned in Kaan, Kas \& Puhland (1990), is that in practice, e.g. in implementations, one is tempted to make rough translations, and to neglect nuances or strong conversational implicatures in natural language, when one is limited to $\exists$ and $\forall$. So, for instance, in Warren \& Pereira (1982) 'a', 'some' and 'the' all are simply interpreted as $\exists$.

\subsection{L(GQ)': a solution}

'I'here are many ways to try and get around the shortcomings of the traditional approach. 'To score better on criterium (i), i.c. to increase expressive power, one could consider the introduction of numbers in the logical formalism. Only, one can imagine that, if made in an ad hoc way, this extension could result in a hybrid formalism (with respect to quantification) showing an even greatcr syntactical mismatch with NL (decreasing the score on criterium ii).

$\Lambda$ solution for these problcms was first explored by Montague (1973), and later thoroughly worked out by Barwise \& Cooper (1981) in a formalism called L(GQ). In contrast to traditional PL, which only has $\exists$ and $\forall$, the language of generalized quantifiers $\mathrm{L}(\mathrm{GQ})$ specifies no limitation of the number of primitives to express quantification. All kinds of determiners can be used. 'The translation of the examples of Fig. 4 to L(GQ)' is given in Fig. 5. Some special notational conventions Barwise \& Cooper introduced, are left out. Fur- 
thermore a relational perspective (see /warts, 1983) is used.

\begin{tabular}{|c|c|}
\hline 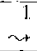 & $\begin{array}{l}\text { Tijn alle werkneners gehuwd? } \\
\text { all }\{a \mid \text { employee }(x)\},\{x \mid \text { married }(x)\})\end{array}$ \\
\hline 2 & Tijn beade werknemers gehuwd? \\
\hline$n$ & the $2(\{x \mid$ ompleyen $(x)\},\{x \mid \operatorname{marricd}(x)\})$ \\
\hline  & $\begin{array}{l}\text { Gijn precies drie werknemers gehuwd? } \\
\text { exactly-i } \\
(\{x \mid \text { employee }(x)\},\{x \mid \operatorname{marticd}(x)\})\end{array}$ \\
\hline$\omega$ & 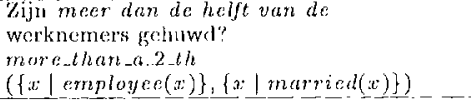 \\
\hline
\end{tabular}

Figure 5: 'Translation of (quantification from Dutch to I. $(G Q)$

'The denotation of $I,((X))$ ' determiners is defined at a meta-level. Some cxamples are given in (1) to (1). In these examples $I$ stands for an interpretation function mapping an expression on its denotation.

$$
\begin{aligned}
& I(\operatorname{all}(\varphi, x))=: \quad \text { I'rue } \quad \text { (if }(I(\varphi) \backslash I(\chi))=\emptyset)
\end{aligned}
$$

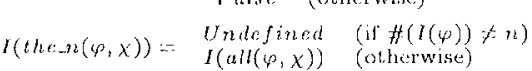



$$
\begin{aligned}
& I(\text { more.than_a_n_th }(\varphi, \chi))= \\
& \begin{array}{l}
\text { True } \quad \text { (if } \#(I(\varphi) \cap I(x))>\#(I(\varphi)) / n) \\
\text { Iralse }
\end{array}
\end{aligned}
$$

In Fig. 5 the structural similarity of the NL expressions is reflected in that of the $\mathrm{I}(\mathrm{GQ})$ ' expressions. l'urthermore, all NI, examples can be expressed almost equally easily in $\mathrm{L}(\mathrm{GQ})^{2}$. By consecuence, the formalism does not force people to be satisfied with rough translations. In short, the problems of traditional logical quantification are overcome.

\subsection{L(GQ)': complications}

Unfortunately, there are two reasons for not considering $\mathrm{I}_{4}(\mathrm{GQ})$ ' an ideal solution. 'The first problem actually is not typical of $\mathrm{L}(\mathrm{G}(\mathrm{Q})$ ), but of the fact that Barwise \& Cooper take over the Montagovian way of coping with possible arnbiguity due to phonomena of quantilier scope. In these cases one reading is generated in a straightforward way by larwise \& Cooper. 'To allow for alternative readings, they introduce extra machinery (called the 'quantification rule').

'The latter mechanism, however convenient from a theoretical point of viow, is rather implementationunfriendly. It operates on complete structural descriptions (=non-trivial trees), and generates complete structural descriptions. Allowing for such a rule drastically changes the profite of the parser that, is needed.

The second problem is that, it is undesirable for CSR, being an interface language with a non-N1,l' module, to contain the set of (NL inspired) determiners that I, GQ ' contains. It would probably be better if GSR had fewer primitives, preferably of a type not com. pletely uncustomary in traditional J)BMSss.

\subsection{GSR: an L(GQ)' derivative}

As a solution for these problems I, (GQ)' gets two new neighbours in the translation process, as shown in Fig. 6.

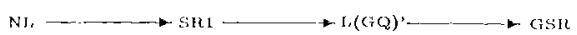

F'igure 6: Major processing steps in the NIP' subsystem

In order to avoid the application of the "quantifi. cation rule', the choice has been to first generate an expression that is neutral with respect to the seope of its quantifiers (SR1), and then solve the scope problem in a sccond step, hereby generating an I,(GQ)' expression. 'The trick of first generating a scope-neutral expression is not new. For instance, it is used in the 1.OQUI system (see Gailly, Ribbens \& Binot, 1990). 'The originality lies rather in the effort to respect well. formedness in the scope-neutral expressions.

Informally speaking, SRI is a predicate- logical formalism in which the argurnents of the predicates are internally structured as the NL arguments of verbs. The most important consequence is that determiners are located within the predicatie-arguments. 'I'o give an example, 'Werken alle werknemers aan twee projekten?' (Do all employees work on two projects?) would be represented as (5). For identity and cardinality questions the formats in lig. 3 are made superfluous by the pseudo-determiners WII and CARI). For instance, the question 'Welke werknemers werken aan twee projekten?' (Which employees work on two projects?') is translated to (6)

$$
\begin{aligned}
& \text { work }(a \ln (\{x \mid \operatorname{ernployec}(x)\}), 2(\{x \mid \operatorname{project}(x)\})) \\
& \text { work }(W H(\{a \mid \operatorname{erm} \operatorname{loyec}(x)\}), 2(\{x \mid \operatorname{project}(x)\}))
\end{aligned}
$$

The translation of NI, to SRI is a straightforward compositional process, comparable to the Barwise \& Cooper processing of readings for which no 'quantification rule' is needed. 'The algorithm for going from Sk1 to L(GQ)' is given in lig. 7.

If an SR1 expression contains a pseudo-determiner WII or CARD, the schema in Fig. 7 is adapted as follows. In the first step the arguments with real determiners are replaced by variables $v_{1}$ up to $v_{n}$, and the argument $W L\left(S_{0}\right)$ or $C, \Lambda R, D\left(S_{0}\right)$ is replaced by a special variable $v_{0}$. liurther, the result $\varphi$ of the normal second step is turned into a set expression or a numerical expression $\left(\left\{v_{0} \mid S_{0} \wedge \varphi\right\}\right.$ or $\left.\#\left(\left\{v_{0} \mid S_{0} \wedge \varphi\right\}\right)\right)$. The third step, which is $\varphi$-internal, remains unchanged.

'The essential part in Fig. 7 is the procedure that de termines the possilsle scope-configurations. In the program only one, the most probable scope-configuration is generated. The algerithm states that the carlier some quantifier occurs in the NL expression, the larger its scope should be in the I, (GQ)' expression. In the 


$$
\begin{aligned}
& P\left(D_{1}\left(S_{1}\right), D_{2}\left(S_{2}\right), \ldots, D_{n}\left(S_{n}\right)\right) \\
& 2\left(s_{2}\right) \\
& \text { Every argument } D_{i}\left(S_{i}\right) \text { is replaced by a new, unique } \\
& \text { variable } v_{i}(i \in\{1, \ldots, n\}) \\
& \ldots P\left(v_{1}, v_{2}, \ldots, v_{n}\right) \ldots \\
& D_{f(1)}\left(\ldots D_{f(2)}\left(\ldots D_{f(n)}\left(\ldots \downarrow_{\downarrow} P\left(v_{1}, v_{2}, \ldots, v_{n}\right) \ldots\right) \ldots\right) \ldots\right) \\
& \text { The remaining lacunes are filled up by adding, as shown, to } \\
& \text { every determiner } D_{i} \text { its original domain-set } S_{i} \text {, and the } \\
& \text { variable } \nu_{i} \text { that was introduced before to replace } \\
& D_{i}\left(S_{i}\right)(i \in\{1, \ldots, n\})
\end{aligned}
$$

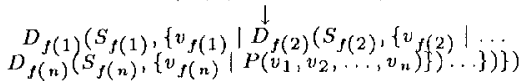

Figure 7: Schema for translation from $\mathrm{SR} 1$ to $\mathrm{L}(\mathrm{GQ})^{\prime}$

NL fragment that was tested cxtensively with the program, this procedure proved to be amazingly accurate (see Speelman, 1992, 85-98). 'I'he future goal, howcver, is that instead of one most probable reading a list of all possible readings, tagged with a degree of probability, is generated. Since the procedure is a separate module, any extension or alteration of can be made without affecting the rest of the program.

What remains to be overcome, is the fact that introducing a large set of determiners in GSR would burden the interpreters used in the database subsystem with an extra, NIP-type recognition task. This problem is solved by giving $\mathrm{L}(\mathrm{GQ})$ ' a righthand neighour (sec) Fig. 6 in which the determiners are replaced by what was originally the meta-level definition of their semantics (see (1)-(4)). In the resulting $L(G Q)$ ' derivative, called GSR, the number of primitives (set, set intersection, set difference, set cardinality, ...) is drastically reduced. Furthermore, the new primitives are much closer to, and even at the heart of, the procedural and semantic building blocks of traditional computer science in general, and of relational DBMSs in particular.

An example of the complete procedure, going from SR1 to L(GQ)' to GSR, is given in (7) up to (9). 'The question is 'Zijn alle werknemers gehuwd?' ( $\Lambda$ re all employees married?).

married(all( $\{x \mid$ employee(x) $\})$

$\operatorname{all}\left(\left\{x_{1} \mid\right.\right.$ employec $\left.\left.\left(x_{1}\right)\right\},\left\{x_{1} \mid \operatorname{married}\left(x_{1}\right)\right\}\right)$

$\left\{x_{1} \mid\right.$ employee $\left.\left(x_{1}\right)\right\} \backslash\left\{x_{1} \mid \operatorname{married}\left(x_{1}\right)\right\}=\emptyset$

\section{FROM GSR TO SQL}

As the NI.P subsystem, the database subsystem is fully implemented. However, we shall restrict ourselves to a very brief sketch of its functionality here. As can be seen in FIg. 2, a GSR expression is first translated to a formalism called IJBSR. 'This was clone for reasons of modularity, primarily for facilitating the extcnsion of the system to difforent target languages.

JBSR, which stands for Datalßase specific Semantic Representation, is a declarative relational database query language that is both close to GSR and easily translatable to any of the commercialized R.JBMS query languages. $\Lambda$ part from the treatment of quantification the formalism is very similar: to rolational calculus. The major effort in the step from GSR to DBSR lies in adapting GSR-terminology to concrete names of tabels and columns of a database. This is done using a DB-lexicon, which can be scen as an augmented FR-model of a database.

The last step, from I)BSR to SQI, is extremely straightforward. Sets and cardinality expressions are translated to (sub)queries. Relations between sets or cardinality expressions are translated to conditions for (sub)queries.

l'or completeness, an example of the database subsystem output is griven. l'or the last cxarrple of tho foregoing section a IDBSR expression and an SQL, query are given in (10) and (11) respectively. Y LS contains only 'Yes'.

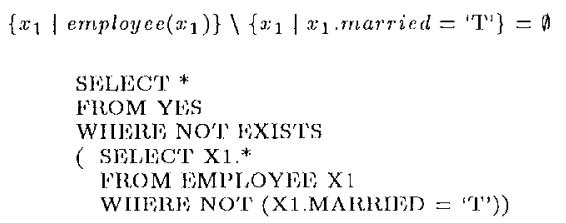

\section{IMPLEMENTATION}

The system is written in Common Lisp (according to the de facto standard Steele,90) and generates standard SQL queries (ISO). It has proved to be a perfectly portable product. Originally written on a Macintos: $\mathrm{SE} / 30$, it has afterwards been tested on several Symbolics, Macintosh and PC platforrms.

The major modules of the linguistic component are a 'letter tree' tool for efficient communication with the lexicon, a transition notwork based morphological analysis tool, and an augmented chart parser for syntactic and scmantic analysis.

\section{CONCLUSION}

In some subficlds of formal semantics the traditional logical apparatus for quantification, i.e. the use of $\exists$ and $\forall$, is being abandoned in lavor of 'generalized quantifiors', because the latter are both closer to ratural language and richer in expressive power. In this text it has been shown how this theory can be put to use in a natural language database interface, another field in which $\exists$ and $\forall$ had bocome traditional. Some modifications had to be made in order to render the theoretical 'generalized quantifier' approach 
more implementation-friendly. 'T'be major modifications were the introduction of a separate module to replace the 'quantification rule', and the shift from meta-level to logical representation of some settheoretical primitives.

\section{References}

[1] Barwise, J. \& Cooper, R. (1981). 'Generalized Quantificrs and Nabural I,anguage'. Linguistics and Philosophy 4, 159-219.

[2] Codd, E.F. (1970). 'A Data Sublangnage Founded on the Rolational Calculus'. ACM SIGFIDLT' Workshop on Data Description, Access and Control, November 1971.

[3] De Roeck, M.N., Lox, C.J., Lowden, B. C'.'T', 'Tur.ner, R. \&. Walls, B.R. (1991). 'A Nalural Latnguage. System Based on Formal Semantics'. l'rocedings of the International Conference on Current lssues in Computational linguistics. 268-281.

[4] Gailly, P.J., Ribbens, 1). \& Binot, J.L. (1990). 'La quantification en 'Traitement, du Language Naturel'.

[5] ISO 'IC97/SC21/WG3 and ANSI X3H2 (1987) ISO 9075 Dalabase Language SQL

[6] Kaan, L., Kas, M. \& Puhlaud, R. (1990). 'Wen procedure voor redeneren met kwantoren'. TABO Bulletin voor T'aalwetenschap 20 (1). 205221.

[7] Montague, R. (1973). "The Proper 'Treatment of Quantification in Ordinary linglish'. Ilintikka J., Moravesik J. \& Suppes P. (eds.) Approaches to Natural lianguage. Dordrecht: Reidcl. 221-212.

[8] Mostowski, $\Lambda .(1957)$. 'On a Generalization of Quantifiers'. I'und. Math. 11, 12-36.

[9] Sowa, J.l' (1991). "lowards the l'xperssive Power of Natural Language'. J.F. Sowa (ed.), Principles of Scmantic Networks. San Mateo, California: Morgan Kaulinann. $157-189$.

[10] Speelman, D). (1992). Licn prototype voor een database-interface in lisp. Vertaling van Noderlandse vrngen natr SQL-queries, Computational Ininguistics 'Thesis, University of Jeuven (in Dutch).

[11] Stecle, (X.l. (1992). Common Lisp : The Language. Second Edition. Digital Press: Bedford M $\Lambda$.

[12] Warren, D.II. \& Pereira, F.C.N. (1982). 'An Lffi cicnt Vasily $\Lambda$ daptable System for Interpreting Natural Language Queries'. Ancrican Joumal of Computational linguistics 8. 110-119.

[13] \%warts, 1". (1983). "Determiners: a relational perspective'. 'Ier Meulen (ed.) S'ludies in Modellheoretio Scmantics. f'oris: Dordrecht. 37-62. 